\title{
Explaining the Early Years of the Euro Exchange Rate: an episode of learning about a new central bank
}

\author{
Manuel Gómez ${ }^{\mathrm{a}}$ and Michael Melvin
}

September 2003

\begin{abstract}
:
Many observers were surprised by the depreciation of the euro after its launch in 1999. Handicapped by a short sample, explanations tended to appeal to anecdotes and lessons learned from the experiences of other currencies. Now sample sizes are just becoming large enough to permit reasonable empirical analyses. This paper begins with a theoretical model of pre- and post-euro foreign exchange trading that generates three possible causes of euro depreciation: a reduction in hedging opportunities due to the elimination of the legacy currencies, asymmetric information due to some traders having superior information regarding shocks to the euro exchange rate, and policy uncertainty on the part of the ECB. One empirical implication of the model is that higher transaction costs associated with the euro than the German mark may have contributed to euro depreciation. However, empirical evidence on percentage spreads tends to reject the hypothesis that percentage spreads were larger on the euro than the mark for all but the first few months. This seems like an unlikely candidate to explain euro depreciation over the prolonged period observed. Reviewing evidence on market dynamics around ECB, Bundesbank, and Federal Reserve meetings, there is no evidence suggesting that the market is "front running" in a different manner than the other central banks. However, we do find empirical support for the euro exchange rate to be affected by learning. By focusing on euro-area inflation as the key fundamental, the model is structured toward the dynamics of learning about ECB policy with regard to inflation. While a stated target inflation rate of 2 percent existed, it may be that market participants had to be convinced that the ECB would, indeed, generate low and stable inflation. The theory motivates an empirical model of Bayesian updating related to market participants learning about the underlying inflation process under the ECB regime. With a prior distribution drawn from the pre-euro EMS experience and updating based upon the realized experience each month following the introduction of the euro, the evidence suggests that it was not until the fall of 2000 that the market assessed a greater than 50 percent probability that the inflation process had changed to a new regime. From this point on, trend depreciation of the euro ends and further increases in the probability of the new inflation process are associated with euro appreciation.
\end{abstract}

${ }^{\mathrm{a}}$ University of Guanajuato, Mexico

${ }^{\mathrm{b}}$ Contact author: Department of Economics, Arizona State University, Tempe, AZ 85287-3806

email: mmelvin@asu.edu

We thank seminar participants at the following universities for their comments on an earlier draft: Arizona State, Bern, Frankfurt, and Tübingen. 


\section{Introduction}

The launch of the euro on January 1, 1999 was the most important international financial event since the end of World War II. This new currency was expected by many to garner immediate acceptance and challenge the role of the dollar as a vehicle currency. Nevertheless, in its infancy its role in the foreign exchange market has been less than what was expected.

As shown by Hartmann (1998), the nations that comprise the European Monetary Union make an economic unit at least as large as the United States. European Union (EU) GDP exceeds US GDP, EU population exceeds US population, EU exports surpass US exports, and outstanding claims in total EU capital markets (bank assets, bonds and equities) are larger than those in the United States. All these indicators would lead us to think that the new currency would challenge the supremacy of the dollar as the most important currency in the world. Nevertheless, the triennial Bank for International Settlements (BIS) survey indicates that the dollar's share of foreign exchange market activity has risen while that of the euro compared to legacy European currencies has fallen. In 1998, the dollar entered on one side of 87 percent of foreign exchange transactions and the legacy euro currencies 53 percent ${ }^{1}$. In 2001, the dollar share rose to 90 percent while the euro's share was but 38 percent. Further evidence is provided in Hau, Killeen and Moore (2002) who show that the average daily dollar/euro volume in foreign exchange trading is nine percent lower than the dollar/DM volume ${ }^{2}$. Moreover, they show that the trade volume of the euro with the yen and the Swiss franc decreased by 44 and 25 percent respectively when compared with the mark. This decrease in volume is striking if we consider that the mark is only one of the legacy currencies in the monetary union.

\footnotetext{
${ }^{1}$ Since there are two currencies involved in every foreign exchange (FX) transaction, the global sum of currencies' shares will equal 200 percent.

${ }^{2}$ They are comparing the average daily volume between the period January 1998 to December 1998 with the period January 1999 to August 1999.
} 
Our focus is not on the volumes traded but on the prices. In particular, we examine theoretically and empirically bid-ask spreads and the level of the euro exchange rate. Hau, Killeen, and Moore argued that wider bid-ask spreads have been important in restricting the role of the euro. Our evidence confirms that this was possible for the level of the spread, at least at the start of euro trading, but is questionable for the percentage spread. Our initial focus is on answering the following: What could lead to wider spreads on the euro than the legacy currencies? What role can the European Central Bank (ECB) play in affecting the dollar/euro spreads? What other institutional features of the market may contribute to higher spreads? Is there reason to expect that wider euro spreads may have been only a short-run phenomenon that will be eliminated over time?

To address these questions, the second section of this paper presents a theoretical model that can explain dollar/euro spreads as a function of expected volatility of the exchange rate due to policy uncertainty on the part of the ECB, the presence of informed traders with prior knowledge of policy actions, and a reduction in hedging opportunities due to the elimination of legacy currency trading. In the third section, we analyze the volatility and spread dynamics of the dollar/euro exchange rate around ECB meetings in order to infer the effects of ECB policy actions (or inaction). In particular we search for evidence that the market was anticipating ECB policy moves in a manner consistent with information leakage. The record of ECB meetings is compared to the earlier meetings of the Bundesbank and the current meetings of the Federal Reserve. We find no evidence to support the hypothesis that the market reaction around ECB meetings differs systematically from that associated with Bundesbank or Federal Reserve meetings. In the fourth section we undertake the task of explaining the level of the exchange rate, arguing that the market was learning about the ECB policymaking process. We model this learning using Bayesian 
updating and show evidence that increments in the market's confidence about the ECB policymaking process have a positive effect on the value of the euro. Section five offers a summary and concludes.

\section{Pre- and Post-Euro Model of FX Trading}

The model is inspired by Hau, Killeen, and Moore and offers three potential explanations for an increase in bid-ask spreads on the dollar/euro exchange rate compared to the legacy dollar/mark exchange rate: reduction of hedging opportunities due to the elimination of important cross rates with the introduction of the euro, an increase in asymmetric information between informed and noise traders and the lack of historical performance of the recently created European central bank and resulting policy uncertainty relative to the Bundesbank.

We describe the behavior of three different market participants: marketmakers, informed traders, and uninformed or noise traders. The marketmakers observe currency demands from both types of traders and choose a bid-ask spread that maximizes their utility. The marketmaker has no way to distinguish the informed from the uninformed traders. The spread that arises from the profit maximizing behavior of the marketmaker depends on parameters that represent the three different factors that we argue explain the wider spread in the dollar/euro market. We will first model the equilibrium spread in the pre-euro period, then in the post-euro era, and finally compare the two to structure our argument.

\subsection{Pre-Euro Period}

For simplicity, it is assumed that before the introduction of the euro, 3 different currencies exist: The dollar (A), the mark (G) and the franc (F). There exists a market maker for each currency pair; we denominate AG the market maker that trades dollar/mark, AF the market maker 
that trades dollar/franc and FG the one that trades franc/mark. The timing in this model is as follows:

Period 1: The market maker AG quotes a bid-ask spread around the midprice $P_{A G}^{M}$. Given this spread, the informed and uninformed traders submit their currency demands. These orders will create temporary inventory imbalance for the market maker AG.

Period 2: Trading occurs in the other two pairs of currencies AF and FG, in which the market makers quote a bid-ask spread around the respective midprice $P_{A F}^{M}$ and $P_{F G}^{M}$. The inventory imbalance created in period 1 for market maker $\mathrm{AG}$ is shared via hedging orders with $\mathrm{AF}$ and FG.

Period 3: The inventories are liquidated at the following prices:

$$
\begin{aligned}
& P_{A G}^{L}=P_{A G}^{M}+\varepsilon_{G} \\
& P_{A F}^{L}=P_{A F}^{M}+\varepsilon_{G} / P_{F G}^{M} \\
& P_{F G}^{L}=P_{F G}^{M}
\end{aligned}
$$

where $\varepsilon$ is a zero-mean, white-noise shock to the liquidation prices. We assume that, pre-euro, the shocks to the liquidation prices come from the G central bank and there is a fixed exchange rate for FG, as F and $\mathrm{G}$ are assumed to belong to a currency union.

As we mentioned before, the market maker AG receives orders from the informed that will be represented by $O^{I}$ while uninformed trader orders are represented by $O^{U}$. The demand for the currency is a function of the spread in the following form: 


$$
\begin{aligned}
& O^{I}(s)=f(s) \chi^{I} \\
& O^{U}(s)=f(s) \chi^{U}
\end{aligned}
$$

Where $\chi^{I}$ and $\chi^{U}$ are assumed to be identical and independently distributed random variables which can take values of -1 and 1 (sell or buy) with equal probability $1 / 2$. The function $f(s)>0$ is assumed to be continuous and decreasing in the spread, it is defined for $s \in(0, \infty)$ and has a maximum at $s=0$.

These demand functions implicitly assume that the uninformed traders do not have information regarding the exchange rate innovations $\varepsilon$, but still respond to changes in transaction costs. The amount of the currency that they are willing to trade fluctuates with the amount of the spread. However, the informed orders $f(s) \chi^{I}$ contain information about $\varepsilon$. This is reflected in the positive covariance between the informed demand and the price innovations:

$$
\operatorname{Cov}\left(\chi^{I}, \varepsilon\right)=\gamma^{G}>0
$$

This assumption implies that informed traders have prior knowledge about price innovations $\varepsilon$. This also implies that the market maker will sustain losses from trading with such agents. Since it is impossible for the dealer to identify types of trader, he/she will manage this risk by hedging these trades through trades with other market makers. In particular, since the currency rate FG has a fixed exchange rate, the inventory imbalance of market maker AG can be hedged via AF trades.

We also assume that the utility function for the market maker depends on the first two moments of their expected profit, specifically: 


$$
\begin{aligned}
& U\left(\prod_{i}\right)=E\left(\prod_{i}\right)-\frac{1}{2} \rho \operatorname{Var}\left(\prod_{i}\right) \\
& \text { for } i=A G, A F, F G
\end{aligned}
$$

Where $\rho$ is the risk-aversion parameter. The expected profit for the market maker consists of two components. The first one is the normal profit $\left(\Pi^{S}\right)$ for providing liquidity, the bid-ask spread, and is represented by,

$$
E\left(\prod_{A G}^{S}\right)=s / 2 \quad E\left[(1-h)\left(\left|O^{I}\right|+\left|O^{U}\right|\right)\right]=(1-h) s f(s)
$$

Where $h$ is the fraction of inventory hedged, and $(0 \leq h \leq 1)$. A higher spread has an ambiguous effect on spread profits because of the negative relationship between spread and trade volume.

The second component of the expected profits $\left(\Pi^{L}\right)$ is the loss from providing quotes to informed traders. This second component is always negative and can be quantified as the covariance of the portion of the aggregate demand for the currency that was not hedged $(1-h)\left(O^{I}+O^{U}\right)$, with the changes in the exchange rate $\varepsilon$, or:

$$
E\left(\prod_{A G}^{L}\right)=-E\left[(1-h)\left(\left|O^{I}\right|+\left|O^{U}\right|\right) \varepsilon_{G}\right]=-(1-h) f(s) \gamma^{G}
$$

To find the profit variance, we first need to note that the variance of $\Pi^{S}$ is zero because its value depends only on the spread and the total number of traders, this implies that the variance of the expected profits is equal to the variance of $\Pi^{L}$. Second, total order flow can take on three values: 


$$
\left|O^{I}\right|+\left|O^{U}\right|=\left\{\begin{array}{cc}
2 f(s) & \text { prob }=1 / 4 \\
0 & \text { prob }=1 / 2 \\
-2 f(s) & \text { prob }=1 / 4
\end{array}\right.
$$

Calculating the unconditional variance of the expected profits as the weighted average of the conditional variance:

$$
\begin{aligned}
\operatorname{Var}\left(\prod_{A G}^{L}\right) & =\frac{1}{4} \operatorname{Var}\left[2(1-h) f(s) \varepsilon_{G}\right]+\frac{1}{4} \operatorname{Var}\left[-2(1-h) f(s) \varepsilon_{G}\right] \\
& =(1-h)^{2} f(s)^{2} \sigma_{\varepsilon_{G}}^{2}+(1-h)^{2} f(s)^{2} \sigma_{\varepsilon_{G}}^{2} \\
& =2(1-h)^{2} f(s)^{2} \sigma_{\varepsilon_{G}}^{2}
\end{aligned}
$$

The utility for the market maker is:

$$
U\left(\prod_{A G}\right)=(1-h) s f(s)-(1-h) f(s) \gamma^{G}-\rho(1-h)^{2} f(s)^{2} \sigma_{\varepsilon_{G}}^{2}
$$

Assuming that competitive entry results in driving the utility to zero, we can solve for the pre-euro spread as:

$$
s^{G}=\gamma^{G}+\rho(1-h) f\left(s^{G}\right) \sigma_{\varepsilon_{G}}^{2}
$$

\subsection{Euro Period}

After the introduction of the euro there are now two currencies: the dollar (A) and euro (E). The market makers AG and AF now trade AE and the third market maker (FG) disappears. In this environment there are no hedging opportunities due to the elimination of the AF and FG markets $(h=0)$, and the assumption that both AE dealers observe the inventory shock. ${ }^{3}$ Now it is assumed that the shock to the liquidation prices comes from the E central bank. Following the

\footnotetext{
${ }^{3}$ Alternatively, one could simply assume that the market is consolidated into one market maker for AE.
} 
same procedure as before, we find the analogous euro period results for expected profits and their variance as:

$$
\begin{gathered}
E\left(\prod_{A E}^{S}\right)=\frac{s}{2} \quad E\left(\left|O^{I}\right|+\left|O^{U}\right|\right)=s f(s) \\
E\left(\prod_{A E}^{L}\right)=-E\left[\left(\left|O^{I}\right|+\left|O^{U}\right|\right) \varepsilon_{E}\right]=-\gamma^{E} f(s) \\
\operatorname{Var}\left(\prod_{A E}^{L}\right)=\operatorname{Var}\left[\left(\left|O^{I}\right|+\left|O^{U}\right|\right) \varepsilon_{E}\right]=2 f(s)^{2} \sigma_{\varepsilon_{E}}^{2}
\end{gathered}
$$

The total utility for the market maker AE is:

$$
U\left(\prod_{A E}\right)=s f(s)-\gamma^{E} f(s)-\rho f(s)^{2} \sigma_{\varepsilon_{E}}^{2}
$$

This implies that the spread for the euro period is defined as:

$$
s^{E}=\gamma^{E}+\rho f\left(s^{E}\right) \sigma_{\varepsilon_{E}}^{2}
$$

\subsection{Pre-Euro versus Euro Period}

When we compare the spreads in the two different periods, it should be clear that in the case of $\gamma^{E}=\gamma^{G}$ and $\sigma_{\varepsilon_{E}}^{2}=\sigma_{\varepsilon_{G}}^{2}$, the spread in the pre-euro period is smaller than the spread in the euro period due to hedging opportunities that lower the exposure of dealers to inventory risk:

$$
\gamma^{E}+\rho f\left(s^{E}\right) \sigma_{\varepsilon_{E}}^{2}>\gamma^{G}+\rho(1-h) f\left(s^{G}\right) \sigma_{\varepsilon_{G}}^{2}
$$


This implies that one source of higher spreads for the euro than the mark is the reduction in hedging opportunities. However, even in the case that hedging is unavailable or unused $(h=0)$, we would expect the same result, $s^{E}>s^{G}$, if the order flows convey more information about forthcoming price innovations $\left(\gamma^{E}>\gamma^{G}\right)$ or if the exchange rate variance in the euro period is greater than the pre-euro period $\left(\sigma_{\varepsilon_{E}}^{2}>\sigma_{\varepsilon_{G}}^{2}\right)$.

With regard to the link between order flow and forthcoming price innovations, we are in the realm of informed traders. On one hand, with the introduction of the euro, it would be reasonable to expect an increase in the number of informed traders. The multinational nature of the ECB, whose General Council consists of the executive board (six members) and the governors of the national central banks, may allow for more information leakage from the policymaking process than existed under the prior system where policy was made in the national central banks. Such information leaks need not emanate from ECB employees, but from representatives of each country that are involved in the policymaking process. Critics of the ECB policymaking arrangement may argue that allegiances are first to the home country and second to Europe. If this is true, national officials assigned to ECB policymaking bodies may provide advance information about future actions of the ECB to the home-government officials and/or representatives of banks and other business firms in their home country. In terms of the model, this would be reflected in $\gamma^{E}>\gamma^{G}$, so we would expect wider spreads on the euro ${ }^{4}$.

On the other hand, the large number of governments and diverse interests involved in the policymaking process creates uncertainty in the market as to what kind of policy will ultimately exist. Actions of the dominant pre-euro central bank, the Bundesbank, were probably more predictable because of a national allegiance to a common goal that may be missing in the case of

\footnotetext{
${ }^{4}$ Bossaerts and Hillion (1991) provide a theoretical model of asymmetric information and spreads in the FX market.
} 
the euro and the ECB. In addition, the Bundesbank had a long record of good performance. With the recently created central bank there is no reference to past behavior that helps agents predict policy. In this sense, the range of likely actions by this new central bank may be wider. This would imply in terms of the model that the expected variability or uncertainty associated with the value of the euro is going to be greater than it was for the pre-euro dominant legacy currency, the mark. We would then expect $\sigma_{\varepsilon_{G}}^{2}<\sigma_{\varepsilon_{E}}^{2}$, so that wider euro spreads should be expected.

We now turn to the empirical evidence to examine what support, if any, the data provide for the hypothesis of wider spreads on the euro compared to the mark. 


\section{Empirical Evidence on Spreads and Volatility}

\subsection{Descriptive Statistics}

We begin this section with descriptive statistics to illustrate the early experience of the euro. It depreciated continuously against the dollar throughout 1999. On a daily basis, it was only slightly more volatile when compared to the strongest currency in Europe before the euro was introduced, the deutsche mark (DM). Perhaps, most interestingly, the euro was traded at wider spreads in 1999 than the mark in prior years.

Our empirical analysis makes use of a data set for the dollar/euro exchange rate consisting of indicative bid-ask quotes posted by Reuters over the period from January 1 to December 31, 1999. In total we have 3,306,829 observations. For purposes of comparison, we employ a similar data set for the mark/dollar exchange rate with more than 1,200,000 observations during the period from January 1 to December 31, 1994. The year 1994 is chosen as a year far enough away from the advent of the euro to be considered "normal" for purposes of comparison. Given that the number of quote arrivals is deepest during European trading hours and quotes are almost nonexistent on weekends, the empirical section of this study excludes all Saturday and Sunday observations and only considers quotes during European business hours on weekdays.

Table 1 provides descriptive statistics for 8:00 to 17:00 London time (GMT adjusted for summer time) for the level of the exchange rate, the first difference of the log-level of the exchange rate, and the spread for the 1994 dollar/mark and 1999 dollar/euro using all the quotes on the Reuters screen. The level of the exchange rate is the average of the bid and ask prices. The first difference of the exchange rate is the change between successive quotes, and the spread is the difference between the ask and bid price. In Table 1.a, we see that the average dollar price of the 
mark was 0.61578 during 1994 and the average dollar price of the euro was 1.06114 during 1999. The range from minimum to maximum value is about 10 cents for the mark and about 19 cents for the euro. Table 1.b shows that the mean change in the log of the dollar/mark exchange rate is positive, reflecting mark appreciation against the dollar in 1994. The average change in the log of the dollar/euro is negative, reflecting euro depreciation during 1999. Note that the standard deviation of both exchange rates is about the same. Even though the volatility is similar for both the mark and euro, Table 1.c shows that the average daily spread for the dollar/euro exchange rate is almost twice the average for the dollar/mark rate. This preliminary look at the data suggests that there may be something more than average volatility explaining the spreads ${ }^{5}$. But table 1.d shows that if the spreads are measured in percentage terms as (ask-bid)/midpoint, then the difference between the spreads on the mark and the euro are much smaller.

Table 2 shows the monthly average levels of the dollar/euro spreads for 1999 . While it is true that spreads on the euro were particularly high early in the year, they are seen to remain much higher than the general level of spreads formerly observed on the mark throughout the year. In terms of percentage spreads, the evidence is not so clear. Figure 1 plots both the daily average level and percentage spreads over the $1999-2000$ period. While there is clearly a downward trend for the level of the spread, the percentage spread has a much less pronounced downward trend in 1999 that appears to end in the late fall of that year. Then for the remainder of the sample, the percentage spread exhibits no particular trend. The decrease in the spreads from the winter into spring 1999 may be related to the effect of ECB actions building a reputation so that the ECB was gaining credibility in the market. This effect will be explored further below.

\footnotetext{
${ }^{5}$ See Bollerslev and Melvin (1994) for theory and empirics linking FX bid-ask spreads and volatility.
} 


\subsection{Central Bank Meeting Days and Volatility}

To focus on differences across the former regime of Bundesbank and mark dominance versus the new regime of ECB and euro, we examine the exchange rate dynamics on days when the Bundesbank or the ECB policy-making committees met to consider interest rate changes. The ECB Governing Council met 23 times in 1999 to consider appropriate interest rate policy (they typically met every other Thursday). On two days, April 8 and November 4, interest rates were changed. The Bundesbank changed interest rates eight times in 1994: March 30, April 20, April 27, May 10, May 18, June 1, June 15, and July 27.

We examine the volatility of the exchange rate on policy shift days. For each day we calculated the squared 1-minute returns as a measure of volatility. ${ }^{6}$ Since we examine the period of European business hours, there are very few minutes with missing quotes, but in these cases, we use the exchange rate taken at the previous minute. Figure 2 illustrates the time path of volatility for meeting days when interest rates were changed. It is immediately obvious that the volatility peaks are greater on the two ECB days than on any of the eight Bundesbank days. Another notable difference between Bundesbank and ECB days of policy changes occurs at the time of the policy news. Vertical lines indicate the time of day that the Bloomberg news service reported the meeting outcome. On the first day that the ECB changed interest rates, April 8, the market appears to have adjusted prior to the news. This is suggested by the rise in volatility prior to the news of the interest rate change so that at the time the news appears publicly, volatility has returned to normal levels. On the next day, November 4, the meeting outcome appears to be news as volatility spikes at the time of the news and then returns to normal levels. This initial view of

\footnotetext{
${ }^{6}$ The squared returns were multiplied by $10,000,000$ to create units with whole numbers.
} 
the data suggests that perhaps the market had knowledge of the April 8 change via leaks from the meeting, but no such evidence of leaks occurred on November 4 nor on any later meeting.

The figures for Bundesbank meeting days show no evidence of market anticipation of the meeting outcome. In fact, the volatility around the time of Bundesbank interest rate changes, suggests that the changes are correctly anticipated. This is consistent with the market having learned over the years how the Bundesbank conducts policy. The evidence is supportive of the hypothesis that the market was learning about ECB behavior so that ECB policy actions generated considerable financial market volatility but there was greater certainty regarding Bundesbank policy making so that Bundesbank policy actions had little discernable effect on exchange rate volatility.

Kim and Verrecchia (1991) derive the result that when an anticipated announcement turns out to be higher quality than anticipated, the price reaction to the announcement increases. In the present context, the dates of ECB meetings are known in advance, so the market anticipates, with some probability, that there will be some price relevant news coming from the ECB on meeting days. On most days, it may be that the quality of the news, in terms of value to market participants, is relatively low, resulting in little, if any, price response. However, on the two days where the ECB took action, the price response was quite dramatic around the time of the news, indicating that the quality of the announcement was higher than anticipated. In this sense, the market is learning about ECB policy making. Days when the ECB makes a policy change are informative to the market for more than just the immediate change in the interest rate. The market is also learning how the ECB conducts policy, so the quality of the news is higher than anticipated on these days. In terms of the theoretical model of Section 2, the greater spread 
associated with the euro compared to the mark may be pricing this volatility or policy uncertainty effect associated with learning about the ECB.

The comparisons of ECB and Bundesbank meeting days may not be entirely fair, as the comparisons are for different years. It could be the case that 1999 simply has more inherent volatility than 1994 and this is reflected in the volatility plots related to the ECB and Bundesbank. As an additional comparison, we examine dollar/euro exchange rate volatility on days when the Federal Reserve Federal Open Market Committee (FOMC) met and changed interest rates in 1999. The squared returns are sampled at 1-minute intervals as before and the data are plotted in Figure 2.c. One FOMC day, June 30, had the highest volatility of all days in Figure 2. Another day, August 24, had volatility comparable to that of the ECB. This suggests that on two meeting days in 1999, the FOMC created news that generated considerable volatility. Note also that the plots in Figure 2.c. have two vertical lines. One represents the official meeting ending time as reported in the minutes of the FOMC meetings and the other represents the time that the meeting outcome was reported by Bloomberg. The Federal Reserve conducts a press conference following every FOMC meeting, and the press conference occurs with some lag after the meeting ends. The volatility spikes for some days in 1999 indicate that the market was adjusting prices prior to the official announcement much like the case of the ECB on April 8.

The comparison of the FOMC and ECB meeting days when interest rates were changed indicates that the exchange rate dynamics on both types of days are somewhat similar. If one interpreted the evidence regarding the April 8 ECB meeting as being consistent with leaks, then one would have to make a similar interpretation of the FOMC days. Rather than leaks, it may simply be that the market was positioning prior to the meeting end in anticipation of the forthcoming interest rate change. In any case, this evidence does not support a view that the 
market dynamics for ECB meeting days differs from that of the Fed in a substantive way that would support the argument that ECB policy may be associated with insider trading or asymmetic information. 


\section{Modeling the exchange rate}

Beyond the issue of the spread and volatility considered so far, most scholars and practitioners would consider a more important issue to be understanding the determinants of exchange rate levels. Sinn and Westermann $(2001,2003)$ explain the weakness of the euro by arguing that holders of black market currency were afraid to convert their old European coins and black market notes into the euro in 2002, so they either spent them on goods and services, whereby the lower demand for money is associated with euro depreciation, or else they exchanged them for dollars prior to the appearance of euro currency. Alquist and Chinn (2001) say that the appreciation of the dollar after 1999 can be explained by U.S.-Euro area productivity differentials; however, the euro was also depreciating against the yen, so that this explanation alone cannot do. Our explanation emphasizes the role of the new central bank and the effect of a lack of ECB credibility on the exchange rate when the market is learning about the ECB policymaking process.

Credibility in the European Central Bank, or the lack of it, has likely played a very important role in the determination of the price of the euro in its infancy. The ECB is not the central bank of one country. It covers the geographical area of 12 different countries, each with its own history, culture and economic background. In addition, the lack of historical performance creates uncertainty about the capability of this new institution in achieving low levels of inflation. Such characteristics initially increased the difficulty of accomplishing the principal mission of this central bank, price stability.

The introduction of a new central bank changed the inflation process in the euro area. Initially, the market had limited information about how committed this body was to maintaining 
low inflation. Even though the ECB stated that the primary objective, as laid down in the Maastricht Treaty, is to maintain price stability. ${ }^{7}$ Rational agents need more than mere announcements to be convinced that the ECB is going to devote all its efforts to accomplish such a goal. They will use all available past and current information to evaluate whether or not the European Central Bank can achieve the target level of inflation.

We hypothesize that beginning in 1999, the market was learning about ECB policymaking by observing the inflation rate in Euroland. Since then, agents are using this information to recognize how different the inflationary process is before and after the introduction of the ECB. We model this learning process using Bayesian updating to calculate the probability that the inflationary process in the euro area has actually changed. The evolution of the probabilities that represent the market's beliefs, and consequently, the effects that learning has on the exchange rate, are computed based on the following assumption: in the event that the inflation process has actually changed, the market knows the parameters of the new process.

In this section we present a simple model that explains the level of the exchange rate and how we construct the probabilities of a new inflation process. Then, we empirically investigate the impact of the market learning about the policymaking of the ECB on the exchange rate of the euro against the U.S. dollar, British pound, and Japanese yen.

\subsection{Evolution of the exchange rate}

We slightly modify the previous model to describe the level of the exchange rate. Here it is assumed that the market believes that exchange rates change for two reasons: the inflation

\footnotetext{
${ }^{7}$ In order to bring about absolute clarity as regards the primary objective, the Governing Council decided to define price stability "as a year-on-year increase of the Harmonised Index of Consumer Prices (HICP) for the euro area of below 2\%”.
} 
differential between Europe and the U.S. and a stochastic shock. In the pre-euro era the dollar/DM exchange rate followed,

$$
P_{A G}^{L}=P_{A G}^{M}+\varphi_{o}+\eta_{G}
$$

where $\varphi_{o}$ is the "old" inflation differential between Europe and the U.S., and $\eta_{G}$ is a stochastic shock. In the post-euro era the exchange rate fluctuates according to:

$$
P_{A E}^{L}=P_{A E}^{M}+\varphi_{n}+\eta_{E}
$$

where $\varphi_{n}$ is the "new" inflation differential between Europe and the U.S., and $\eta_{E}$ is a stochastic shock.

\subsection{Learning about the inflation process}

The market considers that the inflation process in the euro area may have changed due to the creation of the ECB, so that the expected rates of inflation after January 1999 will be different from the ones observed before that date. We assume that the U.S. inflation process has not changed over the sample period, so that the market focuses on the important institutional change in Europe.

The market assumes that inflation in Europe used to be generated by a stationary process given by,

$$
\varphi_{o, t}=\delta_{o}+\xi_{o, t}
$$

Where $\delta_{o}$ is a constant parameter, and $\xi_{o, t}$ is a white noise, normally distributed disturbance term. We fix the prior distribution for inflation by considering the period prior to the 
establishment of the European Monetary Institute (EMI) in 1994. The EMI was the precursor to the ECB and began the process of monetary policy coordination across European Union central banks. Averaging the monthly percentage changes in the consumer price indexes of the euro-area countries over the period January 1990 to December 1993 yields the pre-euro mean and variance for inflation. The prior mean is 0.00334 and the prior variance is 0.000015 . Once the euro begins on January 1, 1999, the market considers that the process might have changed, and now follows,

$$
\varphi_{n, t}=\delta_{n}+\xi_{n, t}
$$

Where $\delta_{n}<\delta_{o}$, and $\xi_{n, t}$ is a white noise normally distributed random variable. Agents are assumed to know the parameters of the new distribution because they have knowledge of the ECB's inflation target.

Given the uncertainty about the true inflation process in Europe, the market assigns a probability $P_{n, t}$ to the event that $\delta$ switched from $\delta_{o}$ to $\delta_{n}$, and $P_{o, t}$ represents the probability that the market assigns to the event that the inflation differential has not changed, and $P_{n, t}+P_{o, t}=1 \quad \forall t$. Subsequently, the market updates these probabilities after observing the realized inflation rate every month according to Bayes' law:

$$
\left(\frac{P_{n, t}}{P_{o, t}}\right)=\frac{P_{n, t-k} f\left(\varphi_{t}, \ldots, \varphi_{t-k} \mid \delta_{n}\right)}{P_{o, t-k} f\left(\varphi_{t}, \ldots, \varphi_{t-k} \mid \delta_{o}\right)}
$$

where $f\left(\varphi_{t}, \ldots, \varphi_{t-k} \mid \delta_{i}\right)$ is the likelihood function of $\varphi_{t}$ given $\delta_{i}$, and the $P_{i, t-k}$ are the prior probabilities at lag $\mathrm{k}$. 
These probabilities reflect the credibility that the ECB has in the market, in particular over its ability to maintain price stability. The evolution of these probabilities over time will depend upon future realizations of the stochastic variable $\varphi$. The posterior probability $P_{n, t}$ will converge to one, if in fact the process has changed, or to zero if there has not been a change.

The exchange rate will be a function of this learning process. If in fact inflation has switched from $\delta_{o}$ to the lower $\delta_{n}$ we would expect appreciation of the euro against other currencies as the market begins to recognize the change.

Given that the probabilities are a recursive function only of the likelihood ratios, if we pick a probability at any point in time, iterating the equation forward or backward would create a unique path of probabilities. Instead of guessing an initial probability in January 1999, we use this characteristic to assume that the market believes that the new process exists by July 2002 . The choice of July 2002 is made based upon a belief that 3.5 years of observations on ECB policymaking is adequate for the market to gain familiarity with the ECB policymaking process. This implies that we are going to calculate these probabilities backward according to,

$$
\left(\frac{P_{n, t-k}}{P_{o, t-k}}\right)=\frac{P_{n, t} f\left(\varphi_{t}, \ldots, \varphi_{t-k} \mid \delta_{o}\right)}{P_{o, t} f\left(\varphi_{t}, \ldots, \varphi_{t-k} \mid \delta_{n}\right)}
$$

\subsection{Constructing the Probabilities}

We compute the parameters of the "old" inflation process using monthly inflation from the pre-EMI period of January 1990 to December $1993 .{ }^{8}$ We omit the period from January 1994 to December 1998, assuming that inflation in these years does not reflect the latent inflationary tendencies of the whole euro area before the introduction of the new central bank, given that in

\footnotetext{
${ }^{8}$ The pre-euro inflation rates were calculated using CPI data from the IMF International Financial Statistics data for 10 countries in the Euro area (Austria, Belgium, Finland, France, Germany, Italy, Luxembourg, Netherlands, Portugal and Spain). Greek data were omitted since Greece did not join the euro-area at the start. Ireland is omitted from the calculation as there are no monthly data for Ireland available for the period.
} 
this period countries were under great pressure to converge to the requirements of the Maastricht Treaty and monetary policy coordination was being discussed in the framework of the EMI.

Similarly, the parameters for the new process $\delta_{n}$ are taken as the inflation target of 2 percent for the mean and the variance is estimated using inflation data from January 1999 to June $2002 .^{9}$

The probabilities are constructed in the manner described by equation (22). The resulting values are reported in Table 3. Table 3 shows the evolution of the probabilities that the inflation process in Europe has switched from the old, pre-euro to the new, post-euro process, given the assumption that the market has learned that there is a new process by July 2002. During 1999, the market does not yet have enough information to judge that the inflation process has changed to $\varphi_{n}$. By November of 2000 the market is convinced with a 62 percent probability that inflation is governed by the new process and the probability never falls below 50 percent again. The very small initial probabilities of less than 1 percent during the first 11 months of 1999, support the hypothesis that much uncertainty existed regarding the ability of the ECB to achieve a low level of inflation. This skepticism started to disappear to a considerable degree by late 2000 .

Figure 3 plots the probabilities that the inflation process has switched along with the dollar, yen, and pound/euro exchange rates. For comparability, the exchange rates were normalized to a value of 1 at the beginning of the sample. It is evident that for small values of the probability, the euro depreciates steadily against all currencies. After the probability is sustained above 50 percent from November, 2000 forward, the trend depreciation stops and there are periods of euro appreciation against the 3 currencies. The evidence in Figure 3 is consistent with the posterior probability of the new, lower inflation process followed by the ECB reaching a critical threshold, after which the euro stabilizes and undergoes runs of appreciation.

\footnotetext{
${ }^{9}$ The inflation rates were calculated using the Harmonised Index of Consumer Prices from the National Statistics Institute of Spain. Data are the original release as received by market participants and not the revised values.
} 


\subsection{Learning effects on the euro exchange rate}

To test the hypothesis that learning about the inflation process affected the euro exchange rate, we model the monthly change in the logarithm of the exchange rate $(\Delta \log (E))$ as the dependent variable, and the change in the probability that euro-area inflation follows a new process $(\triangle P r o b)$ along with a constant term as the independent variables. We estimate the effect of learning about the ECB inflation process on the dollar/euro, pound/euro, and yen/euro exchange rates. ${ }^{10}$ Since the three exchange rates each have the same explanatory variable, efficiency was enhanced by using seemingly-unrelated-regression.

Estimation results are reported in Table 4A. The coefficient estimates and p-values in the first three rows indicate strong support for the learning effect on the exchange rate in the case of the dollar and pound, with $\triangle P r o b$ coefficients of 0.134 and 0.109 and p-values of 0.02 and 0.01 , respectively. The $\triangle$ Prob coefficient on the yen has the expected positive sign but a p-value of only 0.29 . The estimated coefficients imply that a 10 percentage point increase in $\triangle P r o b$ is associated with a 1.3 percent depreciation of the dollar against the euro. Values for the pound and yen are 1.1 and 0.8 percent, respectively. Finally, the R-squares associated with the dollar and pound models are quite high by time-series exchange rate standards and the $\mathrm{Q}$ statistics indicate that the residuals are white noise.

As a robustness exercise, we re-estimated the exchange rate models including the interest differential between each currency and the euro. Specifically, one-month LIBOR rates at the

\footnotetext{
${ }^{10}$ The exchange rate data were retrieved from DataStream.
} 
beginning of each month were retrieved from the British Bankers Association and the dollar-euro, pound-euro, and yen-euro interest differentials were then created. The interest differential at the start of the month should serve as a market predictor of the expected change in the exchange rate over the month. Adding the interest differentials to the models may serve as a summary regarding additional fundamentals relevant to exchange rate determination.

The augmented exchange rate models were estimated via seemingly-unrelated-regressions and the results are reported in Table 4B. The qualitative results regarding the effect of the probability of a change in the inflation regime are unchanged from part A of the table. Both the dollar and the pound have significant depreciation associated with an increase in the probability of a change in the inflation regime. As before, the yen coefficient has the expected positive sign but a p-value of 0.21 .

The interest differentials are seen to all have negative coefficients. As often the case, each of the inflation differentials predicts exchange rate change with the wrong sign in terms of interest rate parity. For example, a positive one-month dollar-euro interest differential at the beginning of the month is associated with dollar appreciation over the month. On average, a euro "carry trade" strategy of shorting the low interest rate currency and taking a long position in the high interest rate currency would have been profitable (transaction costs would reduce the returns). The interest differential coefficients are seen to be statistically significant for the dollar and yen, but not the pound. The key for our analysis is that even with the incorporation of the interest differentials, the effect of changes in the probability of a new inflation process remain significant as determinants of the foreign exchange value of the euro.

An additional robustness check was performed by re-estimating both models with an alternative prior distribution for the computation of the probabilities of a new euro-area inflation 
process. The results so far were based upon a prior distribution for euro-area inflation drawn from the pre-EMI period of January, 1990 to December, 1993. As an alternative, we calculated a prior from the pre-Maastricht-Treaty period of January, 1988 to January, 1992. The Bayesian updating computations were then redone with the alternative prior distribution and used to re-estimate the exchange rate models. The estimated coefficients on the change in the probability of a new euroarea inflation process are very similar to those reported in Table 4 and the statistical significance is as before. The dollar/euro and pound/euro exchange rates are both significantly affected by the change in probability while the yen/euro exchange rate is not. So our results are not being driven by the choice of sample period used to determine the prior distribution. 


\section{Summary and Conclusion}

The experience of the euro in its infancy has provoked much speculation in the search for explanations for the wide bid-ask spreads and steady depreciation. A theoretical model of spread determination was outlined that identifies three important determinants: policy uncertainty associated with the ECB, informed traders with prior knowledge of policy actions, and reduced hedging opportunities due to the elimination of the legacy-European currencies. The latter effect has been well discussed in Hau, Killeen, and Moore, so we do little more than acknowledge its potential importance.

With regard to the policy uncertainty effect, the argument is that the market has no prior record of ECB behavior so that there is learning occurring in the early stages of ECB policy making. We present some suggestive evidence that euro volatility on the first ECB policy action days was much greater than earlier mark volatility on Bundesbank policy action days. This is consistent with the news regarding ECB policy actions helping to resolve the noise associated with ECB Governing Council meetings. Beyond the impact of the immediate change in interest rates announced by the ECB after two meetings in 1999, the policy actions convey important information to the market on how the ECB will conduct policy.

With regard to the asymmetric information effect, the argument is that ECB policy making involves a more heterogeneous group of agents than did Bundesbank policy. One may view the Bundesbank as making policy to achieve national goals with any international goals strictly secondary in importance. So, in a sense, policy makers at the Bundesbank were all "team players" working to achieve a common goal. In the case of the ECB, it may be that the representatives of the member countries have a dual allegiance that results in information leakage. 
This is not to say that leaks come from the ECB staff, but rather the representatives of the national governments who are linked to the Governing Council. There would be great incentive to protect the home market from any harm done by ECB policies. In this case, tipping off a home bank or home government officials to a forthcoming policy change would allow home-market positioning so that no losses are incurred by the ECB policy action. Hard evidence regarding such information asymmetry is essentially impossible to present. However, wide spreads on the euro would be consistent with market makers protecting against the adverse selection probabilities of quoting to an informed trader. In addition, on the day the ECB first changes interest rates, there is a flurry of exchange rate volatility more than an hour prior to the public revelation of the news of the policy action. This is consistent with leakage of the news during the meeting. We point out that this evidence of market anticipation of the policy change was not repeated in later meeting days. So if there was any significant leakage of information, it may have been associated with the start-up of the policy process rather than an ongoing phenomenon. However, we also show intradaily evidence that some FOMC meeting days also have exchange rate volatility spikes prior to the meeting end. So one must be careful not to argue that the ECB is unique in these aspects. The evidence taken as a whole offers little, if any, support for information asymmetries created by leaks from ECB policy meetings.

We also point out that the evidence on wider spreads in the early euro period is greatly reduced if one calculates percentage spreads. Since the euro would be quoted in units greater than 1 in the first year while the mark was quoted in units considerably below 1 , it is not surprising that the (ask-bid) is greater for the euro than the mark. When spreads are measured in percentage terms, there is a much smaller difference between spreads on the euro in 1999 and 
those on the mark. In this regard, there is less support for the argument that the use of the euro has been limited by higher transaction costs.

With respect to the level of the exchange rate, we suggest that the market was learning about the ECB ability to maintain low inflation in Europe. We model this learning using Bayesian estimation and calculate probabilities that reflect the market's beliefs about the ECB's low inflation commitment. The calculated probabilities indicate that it was not until the fall of 2000 that the market assessed a greater than 50 percent probability that the inflation process changed. Exchange rate models were estimated for the dollar/euro, pound/euro, and yen/euro as a function of the change in the probability that the inflation process has changed. Results reveal that increases in the probability of the new inflation process are associated with significant euro appreciation in the case of the dollar/euro and pound/euro. The estimated effect for the yen/euro has the expected sign but is statistically insignificant. The evidence suggests that learning about ECB policymaking was an important fundamental determining the foreign exchange value of the infant euro against the dollar and pound.

The framework presented here is not intended to serve as a general model of exchange rate determination. As the title states, learning about a new ECB and the associated new euro currency should be viewed as an episode in monetary and exchange rate history. Once the ECB established some threshold of credibility regarding its inflation commitment, the trend depreciation of the euro ended and further increases in the probability of a new inflation process for the euro area resulted in euro appreciation. Our results indicate that by November 2000, the probability of a new inflation process for the euro area surpassed 50 percent and never fell below this threshold again. 


\section{References}

Alquist, Ron and Menzie D. Chinn, 2001. " The Euro and the Productivity Puzzle: An Alternative Interpretation." Working Paper, University of California, Santa Cruz and $I M F$.

Bollerslev, T., and Michael Melvin, 1994. "Bid-Ask Spreads and Volatility in the Foreign Exchange Market: An Empirical Analysis.” Journal of International Economics,36:355372.

Bossaerts, P., and Hillion P., 1991. "Market Microstructure Effects of Government Intervention in the Foreign Exchange Market." Review of Financial Studies, 4: 513-541.

Hartmann, P., 1998. Currency Competition and the Foreign Exchange Markets: The Dollar, The Yen and the Euro. Cambridge University Press.

Hau, Harald, William P. Killeen and Michael Moore, 2002. "The Euro as an International Currency: Explaining Puzzling First Evidence from the Foreign Exchange Markets.” Journal of International Money and Finance, 21: 351-384.

Kim, Oliver and Robert Verrecchia, 1991. "Market Reaction to Anticipated Announcements." Journal of Financial Economics, 30:273-309.

Lewis, Karen K., 1989. “Changing Beliefs and Systematic Rational Forecast Errors with Evidence from Foreign Exchange.” American Economic Review, Sept. 1989, 79, 621-636.

Sinn, Hans-Werner, and Frank Westermann, May 2001. "Why has the Euro been falling?" CESifo Working Paper No. 493.

, February 2003, “The Currency Hypothesis of Exchange

Rate Determination," CESifo Working Paper. 
Table 1

DESCRIPTIVE STATISTICS FOR THE MARK AND THE EURO

1.a. Level of the exchange rate

\begin{tabular}{lcc}
\hline & Dollar/DM & Dollar/Euro \\
\hline Mean & 0.61578 & 1.06114 \\
Maximum & 0.67310 & 1.19000 \\
Minimum & 0.56561 & 0.99965 \\
Standard Deviation & 0.02974 & 0.03592
\end{tabular}

1.b. First difference of the Log-level of the exchange rate

\begin{tabular}{lcc}
\hline & Dollar/DM & Dollar/Euro \\
\hline Mean & 1.762 E-07 & $-8.18 \mathrm{E}-08$ \\
Maximum & 0.003223 & 0.00742 \\
Minimum & -0.005350 & -0.00772 \\
Standard Deviation & 0.000198 & 0.00019
\end{tabular}

1.c. Spreads

\begin{tabular}{lcc}
\hline & Dollar/DM & Dollar/Euro \\
\hline Mean & 0.00025 & 0.00047 \\
Maximum & 0.00225 & 0.00360 \\
Minimum & 6.408 E-05 & 0.00001 \\
Standard Deviation & 0.00009 & 0.00019
\end{tabular}

\section{1.d. \% Spreads}

\begin{tabular}{lcc}
\hline & Dollar/DM & Dollar/Euro \\
\hline Mean & 0.00040 & 0.00045 \\
Maximum & 0.00383 & 0.00304 \\
Minimum & 0.00011 & $9.295 \mathrm{E}-06$ \\
Standard Deviation & 0.00015 & 0.00018
\end{tabular}


Table 2

MONTHLY AVERAGE DOLLAR/EURO SPREAD IN 1999

\begin{tabular}{ll} 
Month & Spread \\
\hline January 1999 & 0.000548174 \\
February 1999 & 0.000497459 \\
March 1999 & 0.000517254 \\
April 1999 & 0.000503020 \\
May 1999 & 0.000493815 \\
June 1999 & 0.000474562 \\
July 1999 & 0.000464078 \\
August 1999 & 0.000472378 \\
September 1999 & 0.000463324 \\
October 1999 & 0.000444362 \\
November 1999 & 0.000461528 \\
December 1999 & 0.000466082 \\
\hline
\end{tabular}




\section{Table 3 \\ PROBABILITY THAT THE INFLATION PROCESS HAS SWITCHED}

The probabilities were calculated assuming that the final probability of the old process with mean $\delta_{o}=0.00334483$ is $P_{o, t}=0.01$ and the final probability of the new process with mean $\delta_{n}=0.0016666$ is $P_{n, t}=0.99$.

\begin{tabular}{|c|c|}
\hline Month & $P_{n}$ \\
\hline January 99 & $1.78 \mathrm{E}-05$ \\
\hline February 99 & 2.73 E-05 \\
\hline March 99 & 4.33 E-05 \\
\hline April 99 & $6.88 \mathrm{E}-05$ \\
\hline May 99 & 0.00011 \\
\hline June 99 & 0.00024 \\
\hline July 99 & 0.00047 \\
\hline August 99 & 0.00094 \\
\hline September 99 & 0.00203 \\
\hline October 99 & 0.00399 \\
\hline November 99 & 0.00858 \\
\hline December 99 & 0.01715 \\
\hline January 00 & 0.02729 \\
\hline February 00 & 0.05360 \\
\hline March 00 & 0.08382 \\
\hline April 00 & 0.09225 \\
\hline May 00 & 0.17992 \\
\hline June 00 & 0.32139 \\
\hline July 00 & 0.23910 \\
\hline August 00 & 0.38911 \\
\hline September 00 & 0.55699 \\
\hline October 00 & 0.45969 \\
\hline November 00 & 0.62678 \\
\hline December 00 & 0.73409 \\
\hline January 01 & 0.85629 \\
\hline February 01 & 0.90258 \\
\hline March 01 & 0.76842 \\
\hline April 01 & 0.79401 \\
\hline May 01 & 0.73254 \\
\hline June 01 & 0.51021 \\
\hline July 01 & 0.69208 \\
\hline August 01 & 0.77856 \\
\hline September 01 & 0.87405 \\
\hline October 01 & 0.92077 \\
\hline November 01 & 0.94789 \\
\hline December 01 & 0.96606 \\
\hline January 02 & 0.98309 \\
\hline February 02 & 0.98581 \\
\hline March 02 & 0.99337 \\
\hline April 02 & 0.96561 \\
\hline May 02 & 0.95518 \\
\hline June 02 & 0.97871 \\
\hline
\end{tabular}




\section{Table 4}

THE EFFECT OF INFLATION LEARNING ON THE EXCHANGE RATE

The estimation results reported here are for a model with $\Delta \log (E)$ as the dependent variable, where the exchange rate includes the dollar/euro, pound/euro, and yen/euro. In part A, the independent variable is $\triangle P r o b$, the probability that the market assigns to euro-area inflation following a new process under the ECB. Part B reports results with the addition of the 1-month LIBOR interest differential at the beginning of each month for each currency versus the euro. The sample period is January 1999 to July 2002. P-values are in parentheses.

A.

\begin{tabular}{|l|l|l|l|l|}
\hline $\begin{array}{l}\text { Exchange } \\
\text { Rate }\end{array}$ & Constant & $\Delta$ Prob & $R^{2}$ & $\mathrm{Q}(20)$ \\
\hline$\$ / €$ & $-0.007(0.15)$ & $0.134(0.02)$ & 0.13 & $22.4(0.32)$ \\
\hline$£ / €$ & $-0.004(0.22)$ & $0.109(0.01)$ & 0.16 & $18.7(0.54$ \\
\hline$¥ / €$ & $-0.004(0.46)$ & $0.071(0.29)$ & 0.03 & $14.3(0.82)$ \\
\hline & & & & \\
\hline
\end{tabular}

B.

\begin{tabular}{|l|l|l|l|l|l|}
\hline $\begin{array}{l}\text { Exchange } \\
\text { Rate }\end{array}$ & Constant & AProb & Interest Diff. & $R^{2}$ & $\mathrm{Q}(20)$ \\
\hline$\$ / €$ & $-0.001(0.76)$ & $0.134(0.01)$ & $-0.005(0.04)$ & 0.22 & $23.8(0.25)$ \\
\hline$£ / €$ & $-0.002(0.69)$ & $0.115(0.05)$ & $-0.003(0.15)$ & 0.20 & $21.0(0.40)$ \\
\hline$¥ / €$ & $0.002(0.84)$ & $0.082(0.21)$ & $-0.006(0.07)$ & 0.10 & $15.5(0.75)$ \\
\hline & & & & & \\
\hline
\end{tabular}


Figure 1

Daily average bid-ask spread on the dollarleuro exchange rate

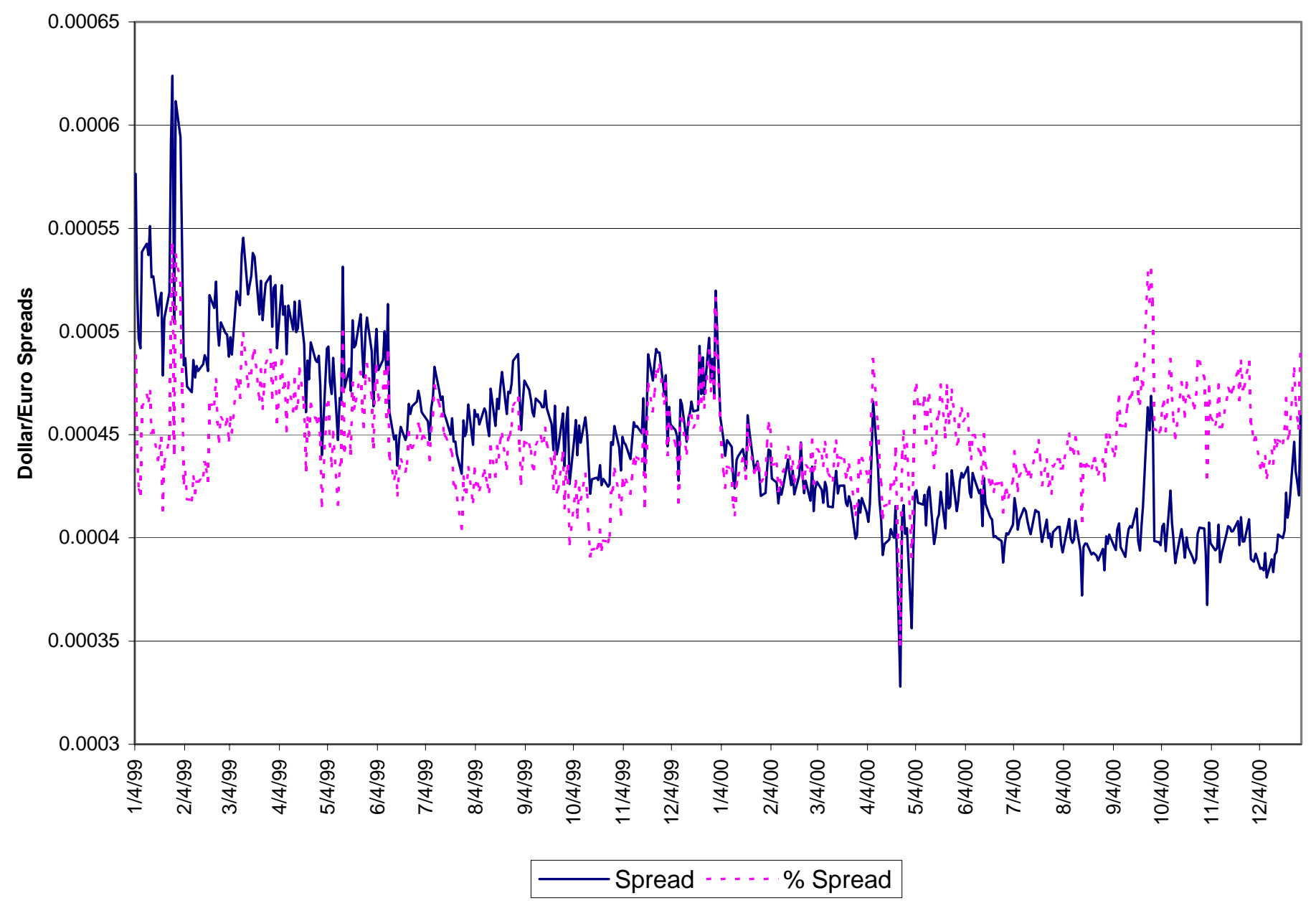


Figure 2: Exchange Rate Volatility on Days of ECB, Federal Reserve, and Bundesbank Policy Actions

The figures plot exchange rate volatility as measured by the square of the change in the log of the dollar/euro exchange rate sampled at 1 -minute intervals (multiplied by 10,000,000). Figures are shown for days when target interest rates were changed for 3 groups: a) ECB meeting days in 1999 and the dollar/euro exchange rate; b) FOMC meeting days in 1999 and the dollar/euro exchange rate; and c) Bundesbank meeting days in 1994 and the dollar/mark exchange rate. Vertical lines in each figure indicate the time of day when the Bloomberg news service reported the change in interest rates resulting from the meeting.

a) ECB Meeting Days:
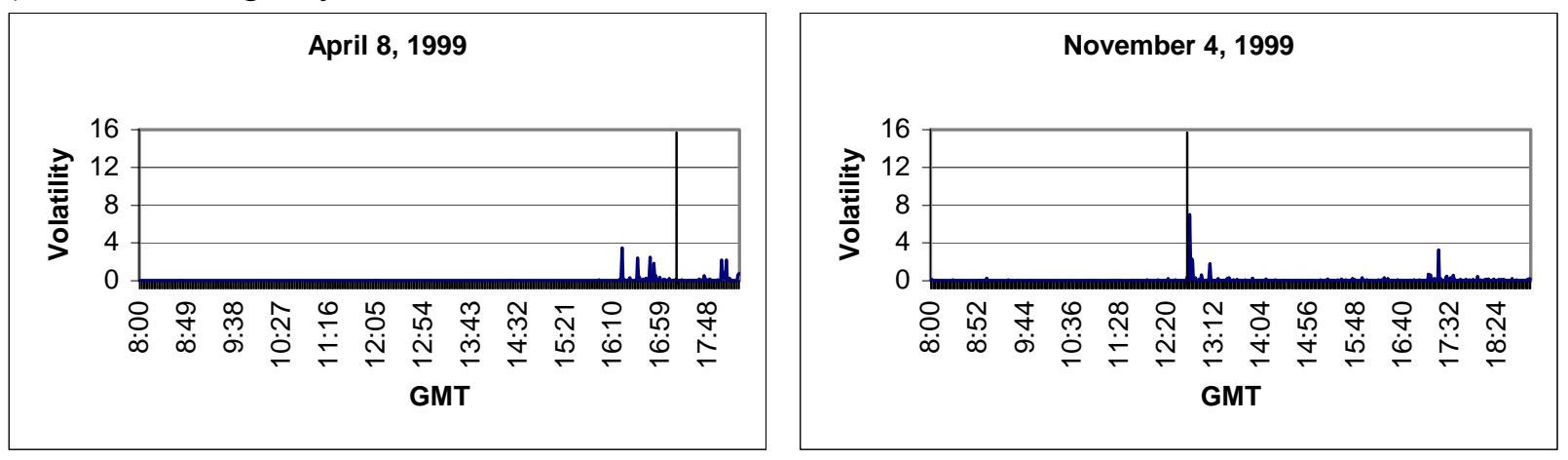

b) BUBA Meeting Days
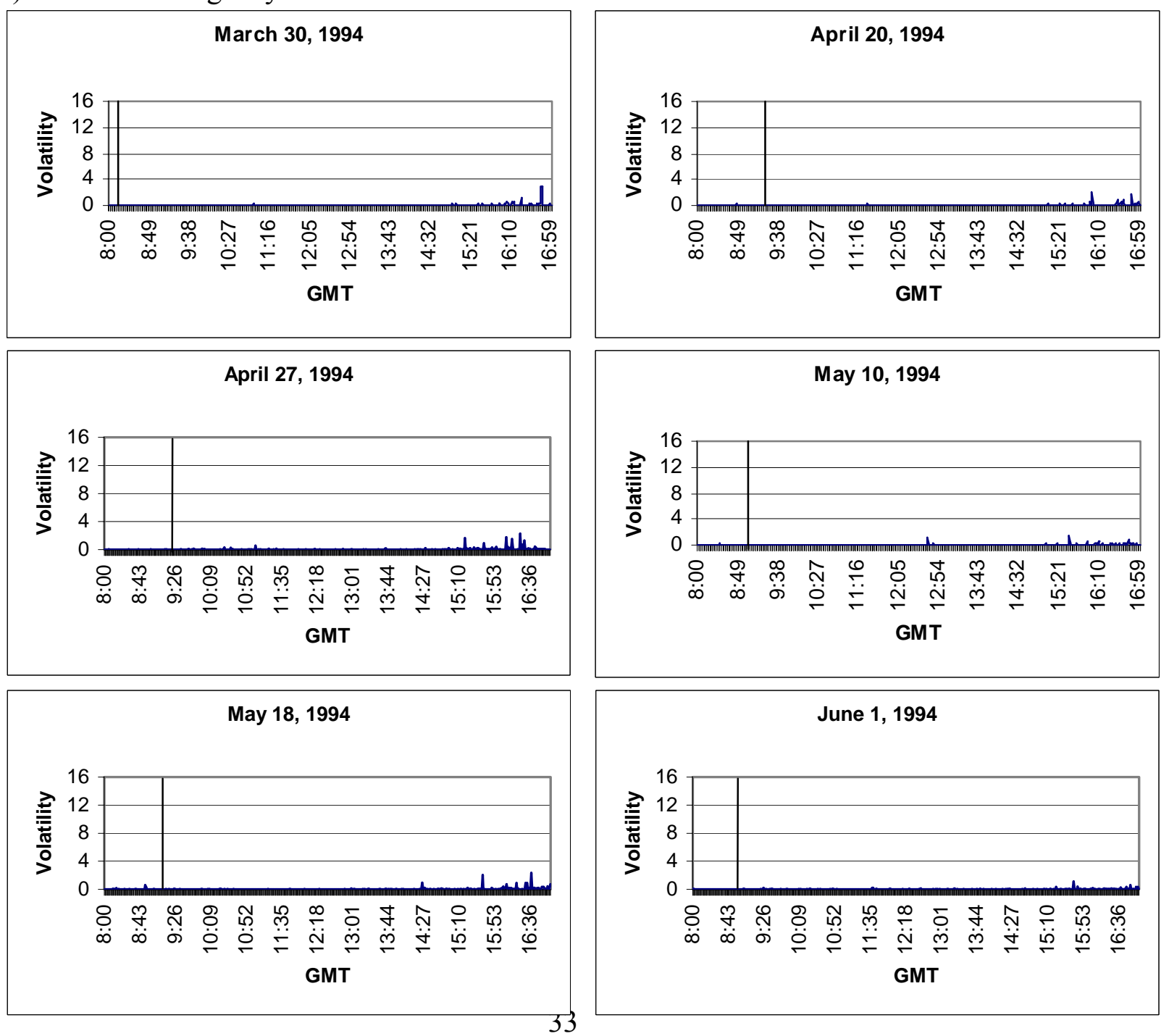

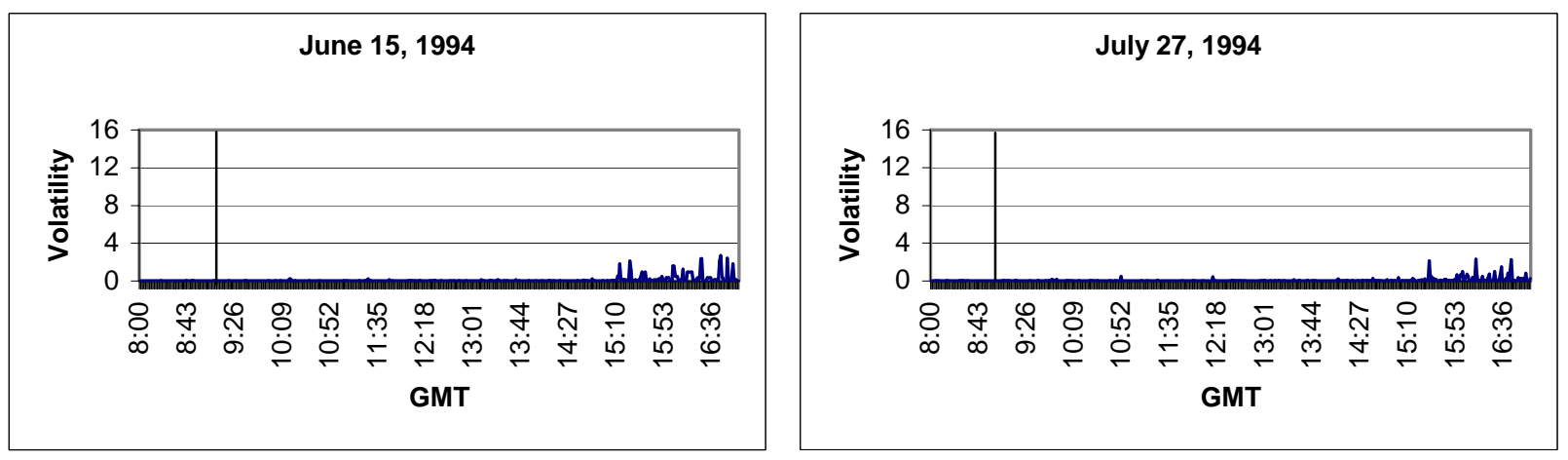

c) FOMC Meeting Days
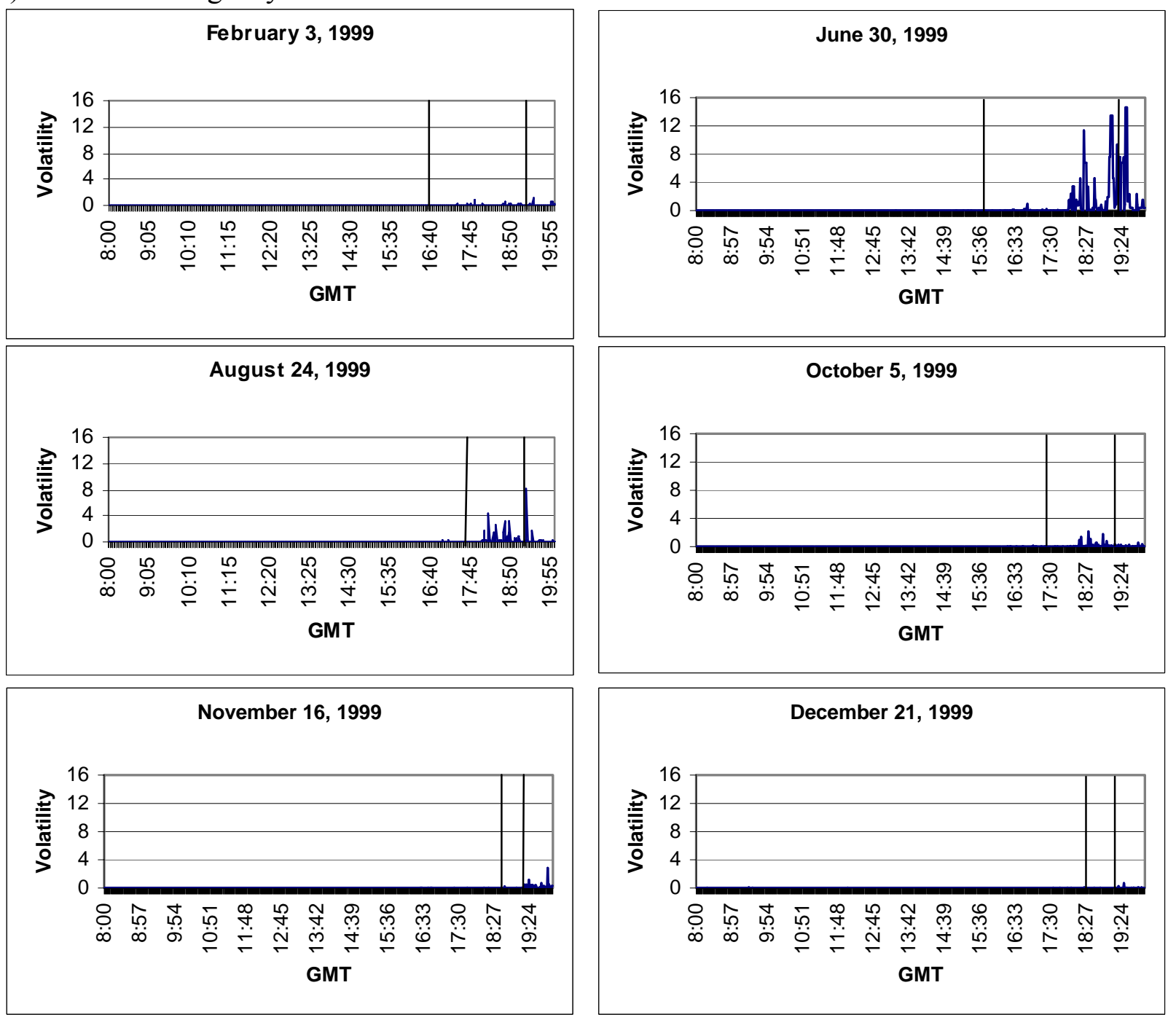
Figure 3: The Probability of a New ECB Inflation Regime and Exchange Rates

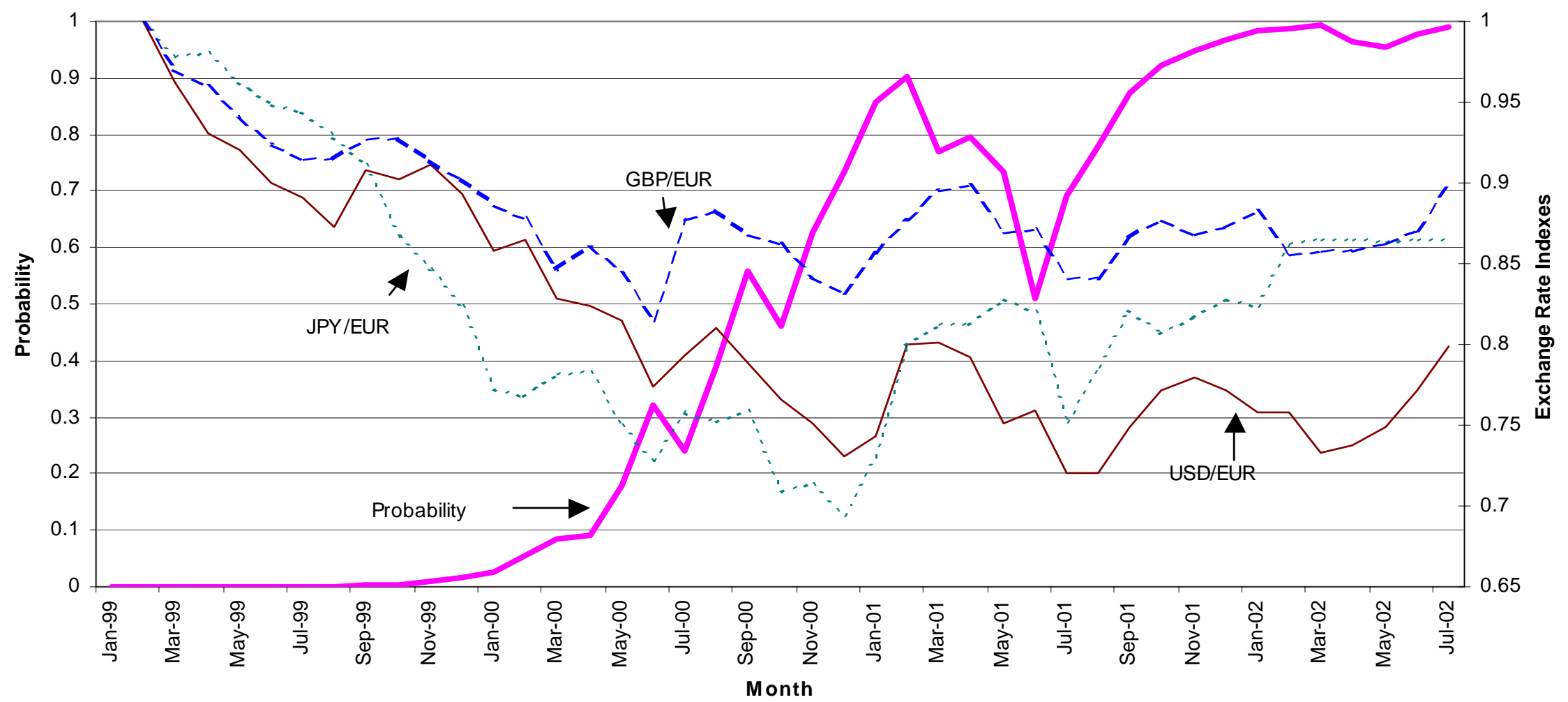

